\title{
Enhancement of Power factor correction and Ripple Free for AC-DC Converter
}

\author{
S. R. V. Ratnam Garlapati ${ }^{1}$, Rajshekar.$S^{2}$ \\ ${ }^{1}$ M.Tech Scholar, EEE Department, ASRIET, Tadepalligudam, AP, India \\ ${ }^{2}$ Assistant Professor, EEE Department, ASRIET, Tadepalligudam, AP, India
}

\begin{abstract}
In this paper, an integrated five-level AC-DC converter is presented. The proposed concept converter integrates the operation of the five-level DC-DC converter and power factor correction. The converter is to operate with two independent controllers, 1) regulates the dc bus and an output controller that regulates the output voltage; 2) an input controller that performs power factor correction. DC bus regulates with level shift PWM technique, this is reduces ripple content in output voltage. This proposed concept compare with three levels AC-DC converter without PWM technique. Simulation results obtained from a MATLAB/SIMULINK are presented to confirm the enhancement of ripple free of the proposed converter.
\end{abstract}

Keywords: Alternative current (AC), Direct Current (DC), Power factor, Pulse width Modulation (PWM).

\section{Introduction}

Day by day Power electronics are advancing their technology rapidly, many converters are designed to achieve better efficiency and to reduce harmonic. Among those multilevel converters plays a major role in increasing demands. To acquiesce harmonic standards like IEC 1000-3-2 most of the AC-DC converters are implemented with PFC. PFC methods are divided into two categories, Passive and active PFC converters.PFC normally be divided into three categories: Passive PFC converters: They use passive elements such as inductors and capacitors to filter small frequency input current harmonics and make the input current more sinusoidal. Although these converters are simple and inexpensive, they are also heavy and bulky and are thus used in a limited number of applications. Two-stage converters: They consist of an ac-dc boost pre-regulator converter that shapes the input current and an isolated $\mathrm{dc}-\mathrm{dc}$ full-bridge converter that converts the pre-regulator output into the required dc voltage. Two-stage converters, however, require two separate switch-mode converters (each with its own controller), and thus, can be expensive. Moreover, they have poor efficiency when operating under light-load modes as there are two converter stages that are operating - each with its own set of fixed losses - while a small amount of power is actually transferred to the load. These fixed losses are dominant under light-load operating modes. 3) Single-stage converters: They can perform PFC/ac-dc conversion and dc$\mathrm{dc}$ conversion with just a single full- bridge converter. There have been numerous publications about single-stage PFC (SSPFC) converters particularly for small-power ac-dc fly back and forward converters [1]-[8]. Research on the topic of greater power ac-dc single-stage full-bridge converters, however, has proved to be more challenging, and thus, there have been much fewer publications [9]-[16]. Previously proposed single-stage ac-dc full-bridge converters have the following drawbacks: a) some are current-fed converters with a boost inductor tied to the input of the full-bridge circuit. Although they can achieve a near-unity input power factor, they lack an energy-storage capacitor across the primary-side dc bus, which can result in the appearance of greater voltage overshoots and ringing across the dc bus. It also causes the output voltage to have a more smallfrequency $120-\mathrm{Hz}$ ripple that limits their applications [10]. b) Some are resonant converters [15], [16] that must be controlled using varying switching-frequency control, which makes it difficult to optimize their design (especially their magnetic components) as they must be able to operate over a wide range of switching frequency. c) Most are voltage-fed, single-stage, pulse width modulation (PWM) converters with a more energy storage capacitor tied across their primary side dc bus. These converters do not have the drawbacks of resonant and current-fed SSPFC converters. They operate with fixed switching frequency, and the bus capacitor prevents voltage overshoots and ringing from appearing across the $\mathrm{dc}$ bus and the $120 \mathrm{-Hz}$ ac component from appearing at the output. Voltage-fed converters, however, have the following drawbacks: i) the primary-side dc-bus voltage of the converter may become excessive under greater input- line and small-output-load modes [10]. This is because SSPFC converters are implemented with just a single controller to control the output voltage, and the dc-bus voltage left unregulated. The greater dc-bus voltage results in the need for greater voltage rated devices and very more bulk capacitors for the dc bus. For example, the converter in [9] has a dc-bus voltage of $600 \mathrm{~V}$. ii) the input power factor of a single-stage voltage-fed converter is not as greater as that of current-fed converters. For example, the converter proposed in [12] has an input current that is neither continuous nor discontinuous, but is -semi continuous" with a considerable amount of distortion.

iii) The converter is made to operate with an output inductor current that is discontinuous for all operation modes or some parts of operation modes [9], [11], to try to prevent the dcbus voltage from becoming more; output inductor current and dc-bus voltage are related, as shown in [11]. Doing so results in the need for components that can handle greater peak currents and additional output filtering to remove ripple. Problems associated with single-stage converters; more dc-bus voltages due to the lack of a dedicated controller to regulate these voltages, more output ripple, distorted input currents, reduced efficiency (particularly for small input line voltages due to a small dc-bus voltage 


\section{International Journal of Science and Research (IJSR) \\ ISSN (Online): 2319-7064}

Index Copernicus Value (2013): 6.14 | Impact Factor (2014): 5.611

normally exist for two-level single-stage converters, such as the ones shown in Fig. 1 and three-level converters [15]. In the paper, a new single-stage ac-dc converter that does not have the drawbacks of previously proposed single-stage and two-stage converters is proposed. The paper introduces the new converter, explains its basic operating principles and its modes of operation, and discusses its features and its design.

\section{Proposed Concept and Three Level Converter}

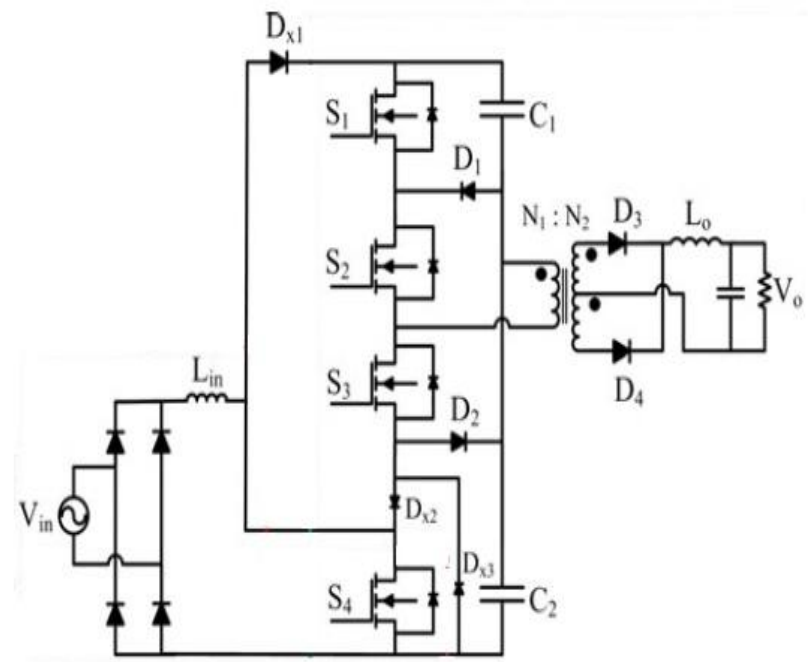

Figure 1: Three Level AC-DC converter

Basic model of three level AC-DC converter is used for power factor correction and improve the output voltage, but the output voltage has some ripple content. Three level AC$\mathrm{DC}$ converter as shown in figure1. Figure 2 shown the modes of operation of three level AC-DC converter, which is divided into eight stages $\left(t_{0}-t_{8}\right)$ in each stage act on gate signals of switch. $\mathrm{V}_{\mathrm{g} 1}$ gate signal of switch $\left(\mathrm{S}_{1}\right), \mathrm{V}_{\mathrm{g} 2}$ gate signal of switch $\left(S_{2}\right), V_{g 3}$ gate signal of switch $\left(S_{3}\right), V_{g 4}$ gate signal of switch $\left(\mathrm{S}_{4}\right), \mathrm{i}_{\mathrm{Lin}}$ input inductor current, $\mathrm{i}_{\mathrm{Lo}}$ output inductor current, $\mathrm{V}_{\text {pri }}$ primary side of transformer voltage. The decoupling of the input controller and output controller can occur because the crossover frequencies of the two loops are very different. The crossover frequency of the input controller, which performs input power factor correction and converts input ac into an intermediate dc-bus voltage (voltage across the two primary-side dc-bus capacitors), is much smaller than that of the output controller, which converts the intermediate dc-bus voltage into the desired output voltage. Since the two crossover frequencies are far apart, it is therefore possible to consider the design of one controller to be separate from that of the other.

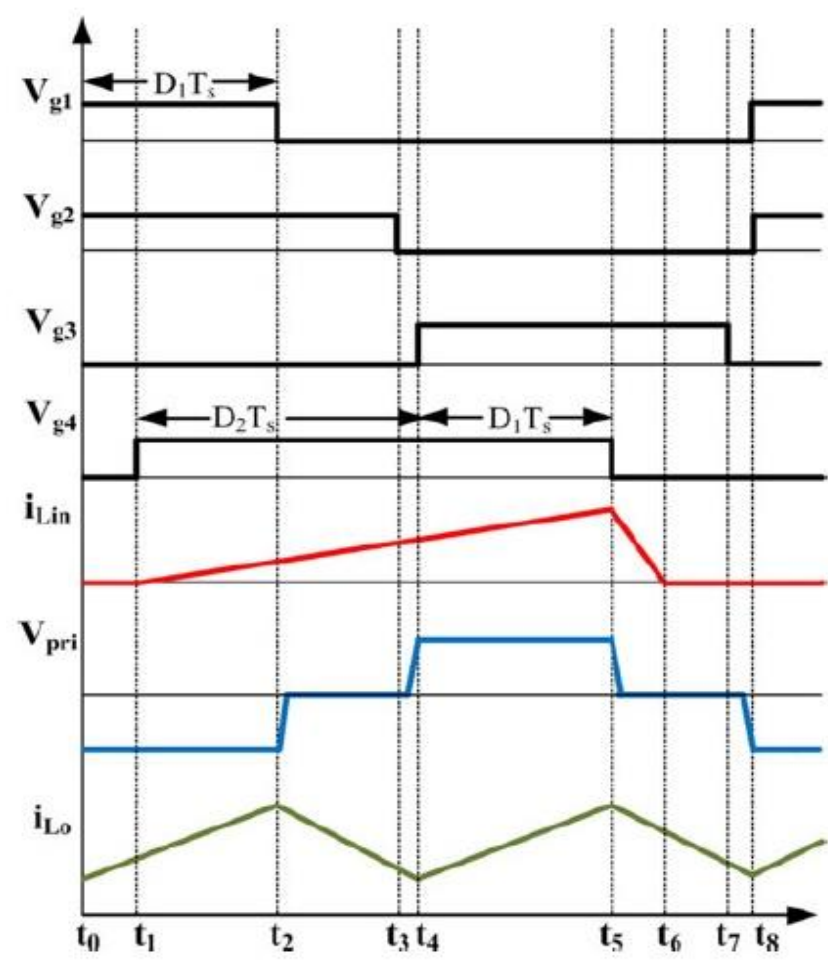

Figure 2: Modes of operation of three level AC-DC converter.

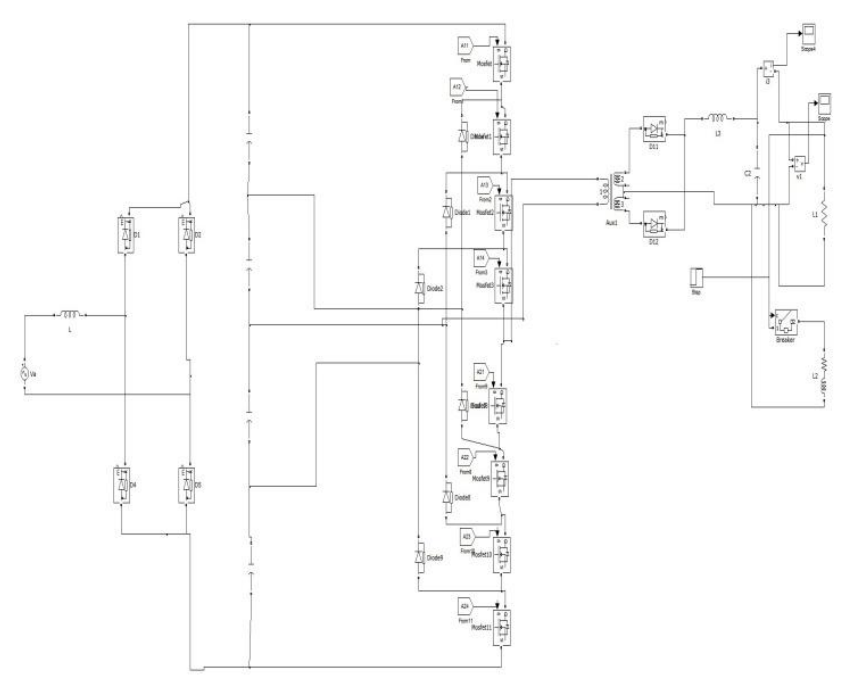

Figure 3: Five Level AC - DC Converter with Level Shift PWM Technique.

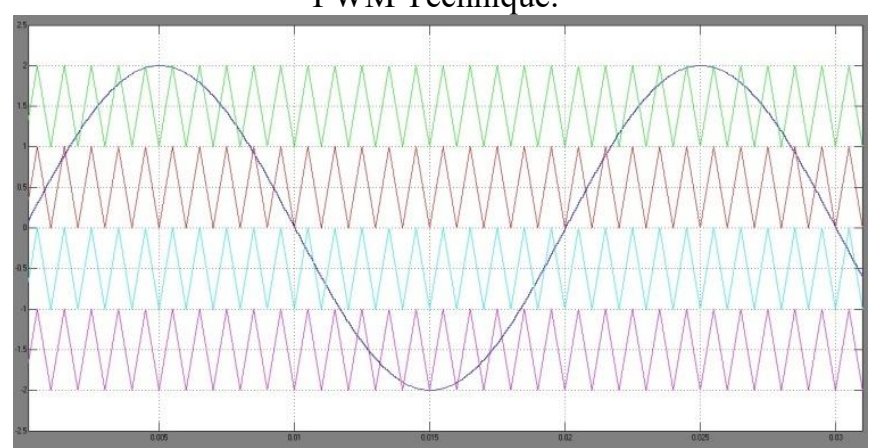

Figure 4: Level Shift PWM Topology. 


\section{International Journal of Science and Research (IJSR) \\ ISSN (Online): 2319-7064}

Index Copernicus Value (2013): 6.14 | Impact Factor (2014): 5.611

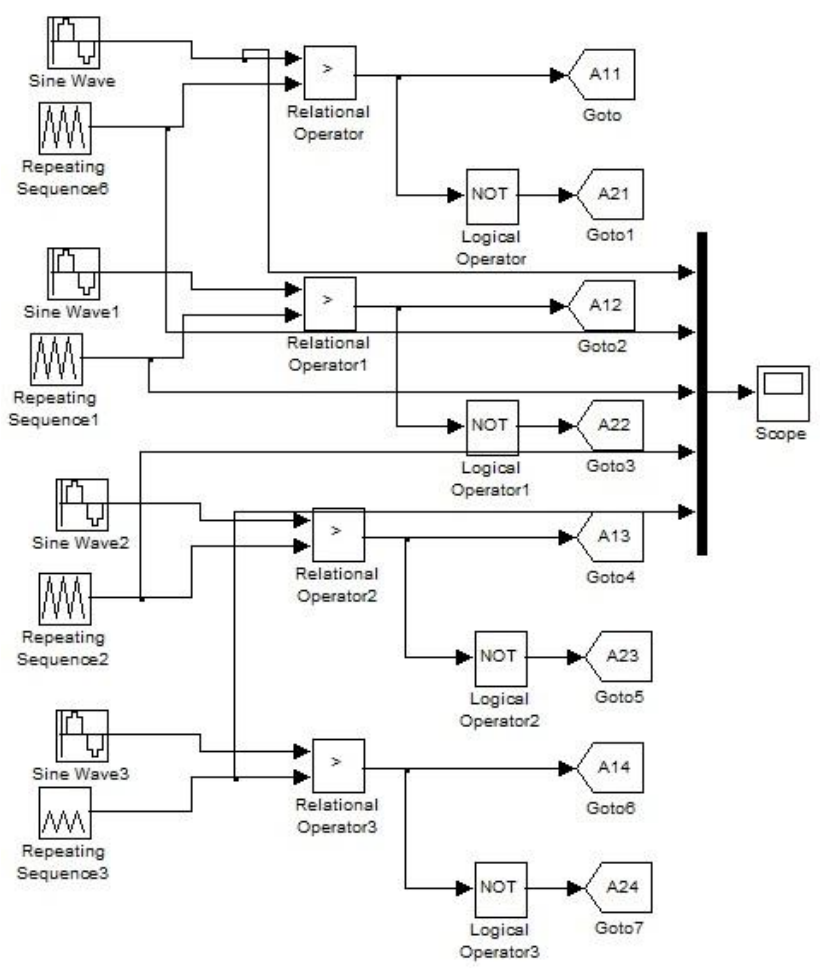

Figure 5: Level Shift PWM topology block diagram

The proposed five level AC-DC converter with level PWM topology shown in Figures 3 to 5. Upper switches are MOSFET's ( $\mathrm{S}_{1}, \mathrm{~S} 2, \mathrm{~S} 3$, and $\left.\mathrm{S} 4\right)$ can operate on pwm (Reference waveform is sinusoidal and Carrier waveform is Triangle, Sinusoidal signal greater than triangle signal generate $\mathrm{ON}$ state and Sinusoidal signal less than triangle signal generate OFF state) signal A11, A12, A13, A14; for down switches can operate on opposite signal of upper switches from A21, A22, A23, A24 as shown in figure 5. The relation between turns ration of main transformer $(\mathrm{N})$

$$
V_{0}=\frac{V_{b u s}}{2 N} D
$$

The minimum value of $\mathrm{N}$ can be found by considering the case when the converter must operate with minimum input line and, thus, minimum primary-side dc-bus voltage $V$ bus, $\min$ and maximum duty cycle $D \max$.

The proposed single-stage converter can operate with a better input power factor for universal input line applications than a single-controller, single-stage because it does have a dedicated controller for its input section that can perform PFC and regulate the dc-bus voltage The presence of a second controller also alsmalls the converter to operate with better efficiency and with ripple free as each section of the converter can be made to operate in an optimal manner.

\section{Simulation Results}

The Proposed converter input voltage is $\mathrm{V}_{\mathrm{rms}}=210-230$ Volts, frequency $50 \mathrm{~Hz}$ as per Indian standards tied to AC side. AC supply converter into Pulsating dc by full bridge rectifier, while removing this ripple content dc supplies by adding filters due to these filters affect the power factor. So power factor improve by developing such as proposed topology.

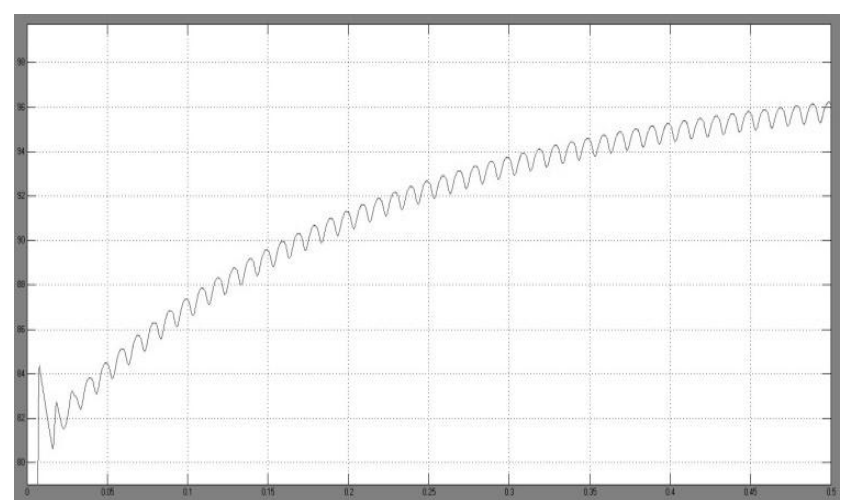

Figure 6: Three Level AC-DC converter output voltage.

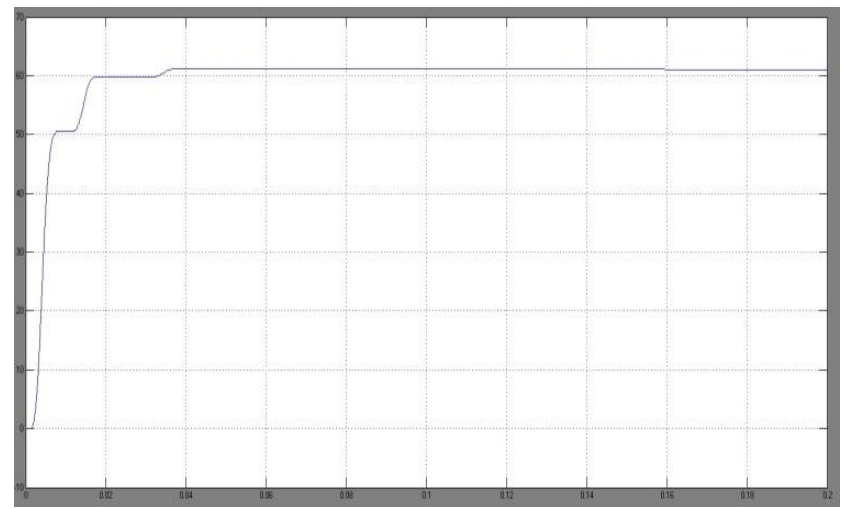

Figure 7: Five Level AC - DC converter with PWM technique output voltage.

Three level AC-DC converter voltage waveform and five level AC-DC converter ouput voltage waveform shown in figure $6 \& 7$. This is the proof of the proposed integrated five level converter improves the ripple free. The average voltage of proposed circuit is 60.5 volts.

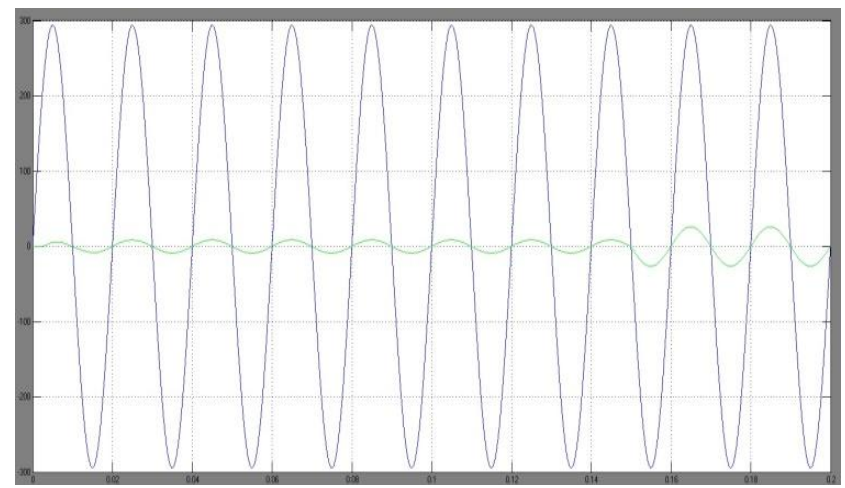

Figure 8: Proposed Five Level AC-DC Converter input side Power Factor.

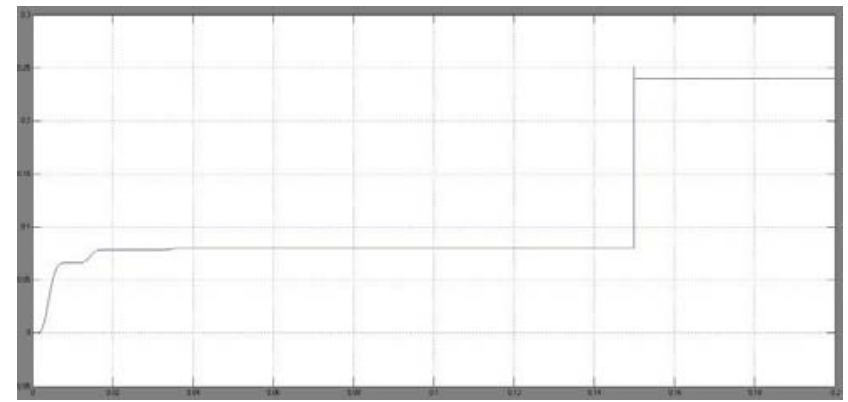

Figure 9: Current Waveform of Proposed Converter.

In this proposed concept different individual loads are connected. In figure $8 \& 9$ shows the current variation on 


\section{International Journal of Science and Research (IJSR) \\ ISSN (Online): 2319-7064}

Index Copernicus Value (2013): 6.14 | Impact Factor (2014): 5.611

load and input power factor also maintain constant. Inductive load operated at 0.25 seconds load current rise from 0.08 amperes to 0.24 amperes. Even inductive load connected the power factor no changes as shown in figure 8 .

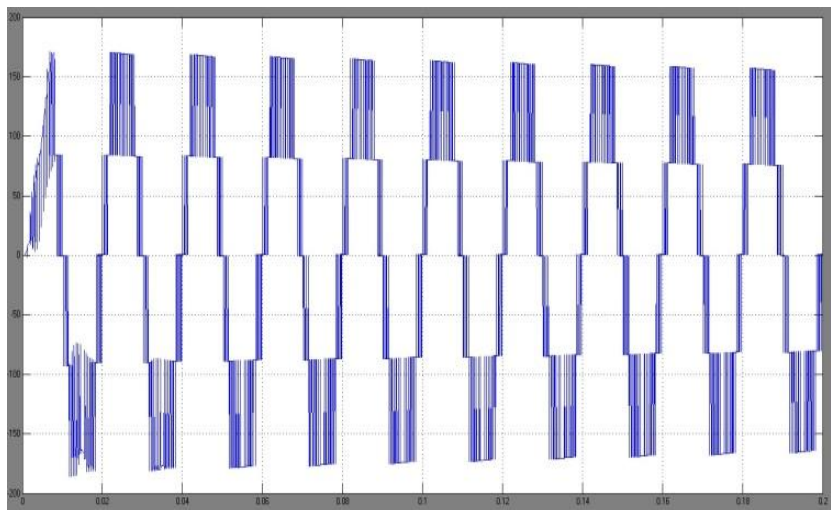

Figure 10: Five level voltage at Second stage of proposed converter.

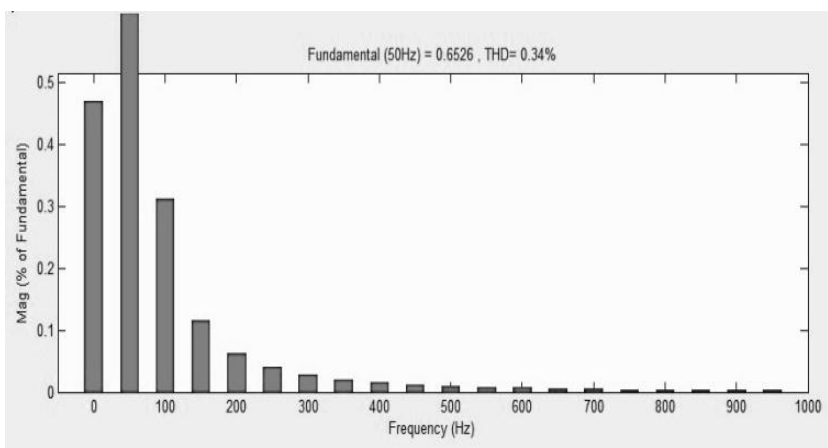

Figure 11: Source current THD \% in Three Level AC-DC converter.

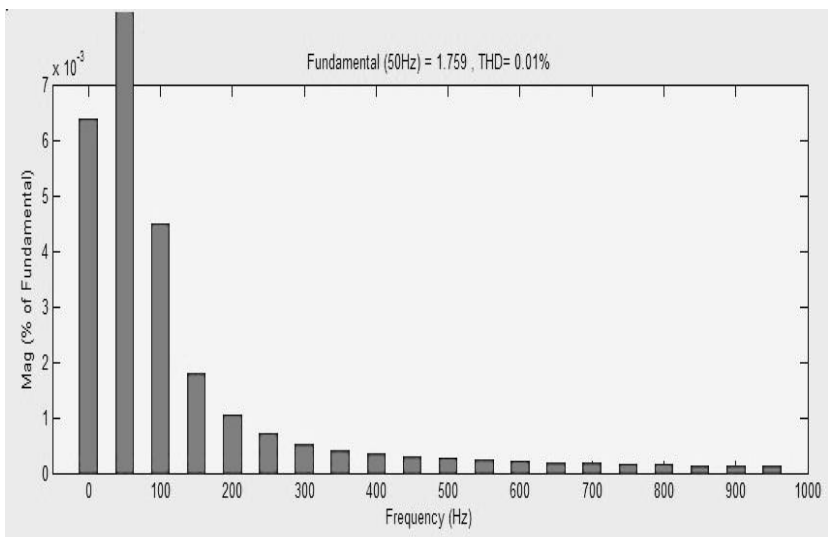

Figure 12: Source Current THD\% in Five Level AC-DC Converter.

Total Harmonics distortion (THD\%) of source current for three level AC-DC converter and Five level AC-DC converter are $0.31 \%$ and $0.01 \%$.

Table 1: Comparison of Three level \& Five level AC-DC converter

\begin{tabular}{|c|c|c|c|}
\hline Levels & THD \% & Power Factor & Ripple Free \\
\hline Three Level & 0.31 & High & Low \\
\hline Five Level & $0.01 \%$ & High & High \\
\hline
\end{tabular}

\section{Conclusion}

A proposed five level integrated single-stage ac-dc converter has better performance as compare to three level AC-DC converters. MATLAB/SIMULINK results showed the performance of proposed circuit ripple free, power factor correction and THD\%. This well operated with two controllers one controller regulates the output voltage and a second performs input PFC. The optimal feature of this converter is that it combines the performance of two-stage converters.

\section{References}

[1] A. Bonnaccorsi, $\bigoplus n$ the Relationship between Firm Size and Export Intensity," Journal of International Business Studies, XXIII (4), pp. 605-635, 1992 (journal style)

[2] J.-Y. Lee, Single-stage AC/DC converter with inputcurrent dead-zone control for wide input voltage ranges," IEEE Trans. Ind. Electron., vol. 54, no. 2, pp. 724-732, Apr. 2007.

[3] D. D.-C. Lu, H. H.-C. Iu, and V. Pjevalica, A singlestage AC/DC converter with high power factor, regulated bus voltage, and output voltage," IEEE Trans. Power Electron., vol. 23, no. 1, pp. 218-228, Jan. 2008.

[4] H. Ma, Y. Ji, and Y. Xu, Đesign and analysis of single-stage power factor correction converter with a feedback winding," IEEE Trans. Power Electron., vol. 25, no. 6, pp. 1460-1470, Jun. 2010.

[5] H. S. Athab and D. D.-C. Lu, - Ahigh-efficiency ac/dc converter with quasi-active power factor correction," IEEE Trans. Power Electron., vol. 25, no. 5, p. 1103 1109, May 2010.

[6] J. M. Kwon, W. Y. Choi, and B. H. Kwon, Singlestage quasi-resonant flyback converter for a costeffective PDP sustain power module," IEEE Trans. Ind. Electron., vol. 58, no. 6, pp. 2372-2377, Jun. 2011.

[7] H. J. Chiu, Y. K. Lo, H. C. Lee, S. J. Cheng, Y. C. Yan, C. Y. Lin, T. H. Wang, and S. C. Mou, -A single-stage soft-switching flyback converter for power-factor-correction applications," IEEE Trans. Ind. Electron., vol. 57, no. 6, pp. 2187-2190, Jun. 2011.

[8] H. Athab and D. Lu, - Asingle-switch ac/dc flyback converter using a CCM/DCM quasi-active power factor correction front-end," IEEE Trans. Ind. Electron., vol. 59, no. 3, pp. 1517-1526, Mar. 2012.

[9] P. K. Jain, J. R. Espinoza, and N. Ismail, -Asinglestage zero-voltage zero-current-switched full-bridge DC power supply with extended load power range," IEEE Trans. Ind. Electron., vol. 46, no. 2, pp. 261270, Apr. 1999.

[10] G. Moschopoulos, -Asimple AC-DC PWM fullbridge converter with integrated power-factor correction," IEEE Trans. Ind. Electron., vol. 50, no. 6, pp. 1290-1297, Dec. 2003.

[11] G. Moschopoulos, Q. Mei, H. Pinheiro, and P. Jain, PWM full-bridge converter with natural input power factor correction," IEEE Trans. Aerosp. Electron. Syst., vol. 39, no. 2, pp. 660-674, Apr. 2003. 


\section{International Journal of Science and Research (IJSR) \\ ISSN (Online): 2319-7064}

Index Copernicus Value (2013): 6.14 | Impact Factor (2014): 5.611

[12] P. Das, S. Li, and G. Moschopoulos, -Animproved AC-DC single-stage full-bridge converter with reduced DC bus voltage," IEEE Trans. Ind. Electron., vol. 56, no. 12, pp. 4882-4893, Dec. 2009.

[13] M. S. Agamy and P. K. Jain, -Athree-level resonant single-stage power factor correction converter: analysis, design, and implementation industrial electronics," IEEE Trans. Ind. Electron., vol. 56, no. 6, pp. 2095-2107, Jun. 2009.

[14] H. L. Cheng, Y. C. Hsieh, and C. S. Lin, -Anovel single-stage high power factor ac/dc converter featuring high circuit efficiency," IEEE Trans. Ind. Electron., vol. 58, no. 2, pp. 524-532, Feb. 2011.

[15] M. S. Agamy and P. K. Jain, - Avariable frequency phase-shift modulated three-level resonant singlestage power factor correction converter," IEEE Trans. Power Electron., vol. 23, no. 5, pp. 2290-2300, Sep. 2009.

[16] M. S. Agamy and P. K. Jain, - adaptive energy storage technique for efficiency improvement of single-stage three-level resonant AC/DC converters," IEEE Trans. Power Electron., vol. 47, no. 1, pp. 176184, Sep. 2011. 